\title{
A (in)visibilidade do direito sanitário na formação de profissionais da enfermagem e do direito ${ }^{1^{*}}$
}

\section{The (in)visibility of sanitary law in the academic education of nursing and law professionals.}

\section{A (in) visibilidad de salud derecho en enfermería de formación profesional y derecho.}

1 * Agradecimento a Fundação Cearense de Apoio ao Desenvolvimento Científico e Tecnológico do Ceará - FUNCAP pelo apoio no desenvolvimento desta pesquisa.

Maria Socorro de Araújo Dias ${ }^{1}$ Diógenes Farias Gomes ${ }^{2}$ Thaís Araújo Dias ${ }^{3}$

Manoel de Castro Carneiro Neto ${ }^{3}$ Maria da Conceição Coelho Brito ${ }^{2}$ Lielma Carla Chagas da Silva ${ }^{2}$

RESUMO: Este artigo investiga o ensino do Direito Sanitário nos bacharelados em Enfermagem e em Direito. Construído em uma interface exploratória, compreensiva e documental, de natureza qualitativa, foi realizado no período de maio de 2015 a fevereiro de 2016. A coleta de informações pautou-se em duas unidades de análise: uma documental (projetos pedagógicos de curso) e outra de docentes e discentes de cursos bacharelados de Direito e de Enfermagem de um Estado do Nordeste brasileiro. Participaram 108 (57,2\%) discentes e 81 (42,8\%) docentes, perfazendo um total de 189 participantes, para os quais foram enviados questionários on-line por meio do Survey Monkey. O estudo do material coletado foi orientado pela Análise Temática. Os resultados identificados a partir dos projetos pedagógicos dos cursos demonstram a incipiência na indução da formação para o campo do Direito Sanitário enquanto instrumento de operacionalização do Direito à Saúde. São projetos vinculados a escassas discussões que se dão, por vezes, em disciplinas/módulos optativos e direcionados ao entendimento do Direito à Saúde. Resultado semelhante foi obtido com os docentes e discentes. Destes, 100 participantes afirmaram que inexiste o ensino do Direito Sanitário e 89, que é um conteúdo associado a outras abordagens, não configurando uma disciplina específica. Constatou-se, portanto, uma inexpressividade do ensino do Direito Sanitário nos cursos estudados evidenciando que a formação em Enfermagem e Direito estão em descompasso com a tendência fenomenológica das situações jurídicas cada vez mais crescentes na saúde.

\footnotetext{
1 Universidade Estadual Vale do Acaraú. Escola de Formação em Saúde da Família Visconde de Sabóia

2 Universidade Federal do Ceará

3 Universidade Estadual Vale do Acaraú
}

ISSN 1982-8829 Tempus, actas de saúde colet, Brasília, 11(4), 221-236, dez, 2017. Epub Ago/2018 
Palavras-chave: Direito Sanitário. Enfermagem. Direito. Ensino. Desenvolvimento de pessoal.

\begin{abstract}
This article investigates the teaching of Health Law in Nursing and Law bachelors. Built in an exploratory, comprehensive and documentary interface of a qualitative nature, it was carried out from May 2015 to February 2016. The collection of information was based on two units of analysis: a documentary (pedagogical projects of course) and another of teachers and students of Bachelor of Law and Nursing courses in a state of Northeast Brazil. Participants included 108 $(57.2 \%)$ students and $81(42.8 \%)$ teachers, for a total of 189 participants, for whom questionnaires were sent online through Survey Monkey. The study of the collected material was guided by the Thematic Analysis. The results identified from the pedagogical projects of the courses demonstrate the incipience in the induction of training for the field of Sanitary Law as an instrument for the operationalization of the Right to Health. These projects are linked to scant discussions that sometimes take place in optional disciplines / modules and directed to the understanding of the Right to Health. Similar results were obtained with teachers and students. Of these, 100 participants stated that there is no teaching of health law and 89 that is an associated content for other approaches, not configuring a specific discipline. Therefore, there was an inexpressiveness of the teaching of Sanitary Law in the courses studied, evidencing that the Nursing and Law training are in disrepair with the phenomenological tendency of the legal situations increasing in health.
\end{abstract}

Keywords: Health Law. Nursing. Law. Teaching. Staff Development.

RESUMEN: Este artículo investiga la enseñanza del Derecho Sanitario en los bachilleratos en Enfermería y en Derecho. En el período de mayo de 2015 a febrero de 2016. La recolección de informaciones se basó en dos unidades de análisis: una documental (proyectos pedagógicos de curso), y otra en la que se desarrolló en una interfaz exploratoria, comprensiva y documental, de naturaleza cualitativa, de docentes y discentes de cursos bachillerados de Derecho y de Enfermería de un estado del Nordeste brasileño. Participaron 108 (57,2\%) discentes y 81 (42,8\%) docentes, totalizando un total de 189 participantes, para los cuales se enviaron cuestionarios online a través del Survey Monkey. El estudio del material recolectado fue orientado por el Análisis Temático. Los resultados identificados a partir de los proyectos pedagógicos de los cursos demuestran la incipiencia en la inducción de la formación para el campo del Derecho Sanitario como instrumento de operacionalización del Derecho a la Salud. Son proyectos vinculados a escasas discusiones que se dan a veces en disciplinas / módulos optativos y dirigidos al entendimiento del Derecho a la Salud. Resultado semejante fue obtenido con los docentes y discentes. De estos, 100 participantes afirmaron que no existe la enseñanza del derecho sanitario y 89 que es un contenido asociado hay otros enfoques, no configurando una disciplina específica. Se constató, por lo tanto, una inexpresividad de la enseñanza del Derecho Sanitario en los cursos estudiados, evidenciando que la formación en Enfermería y Derecho están en descompás con la tendencia fenomenológica de las situaciones jurídicas cada vez más creciente en la salud.

Palabras clave: Derecho Sanitario. Enfermería. Derecho. Enseñanza. Desarrollo de Personal. 


\section{INTRODUÇÃO}

O Sistema Único de Saúde (SUS), considerado uma das maiores conquistas sociais previstas na Constituição Federal (CF) de 1988, consagra os princípios da universalidade, equidade e integralidade da atenção à saúde da população ao estabelecer, em seu art. nº 196, que:

A saúde é direito de todos e dever do Estado, garantido mediante políticas sociais e econômicas que visem à redução do risco de doença e de outros agravos e ao acesso universal e igualitário às ações e serviços para sua promoção, proteção e recuperação. ${ }^{1}$

Complementarmente, o caput do art. $2^{\circ}$ da Lei $\mathrm{n}^{\circ}$ 8.080, de 19 de setembro de 1990, dispõe que "a saúde é um direito fundamental do ser humano, devendo o Estado prover as condições indispensáveis ao seu pleno exercício". Dessa maneira, compreende-se que o SUS representa um sistema de saúde baseado em princípios e valores inovadores, com potencial para garantir o acesso universal da população a bens e serviços que garantam saúde e bem-estar de forma equânime e integral. $^{2}$

Ao direcionar o olhar para a administração do SUS, Magalhães Júnior ${ }^{3}$ deflagra que somente consensos interfederativos serão capazes de decidir os rumos do sistema de saúde ao propor uma nova administração pública negocial-consensual. Refere que esse sistema tem sido a única política universalista brasileira que considera, na sua essência, o ser humano como sujeito de direitos perante o Estado.

Dessa maneira, D'Ávila e Saliba ${ }^{4}$ consideram os movimentos pelo direito à saúde como um exercício permanente. Tal exercício envolve a complexidade da implementação do conceito ampliado de saúde (saúde como bem viver) e de uma equação inexata entre financiamento do setor saúde e necessidades expressas pela população. O que se verifica, com recorrência, é a intervenção do Poder Judiciário junto ao Poder Executivo para fins de efetivação das obrigações deste, o que tem desencadeado o fenômeno da judicialização da saúde no Brasil e em outros países latinoamericanos como a Argentina, Costa Rica e Colômbia., ${ }^{5,6}$ Contrapondo-se a esse fenômeno, há responsabilidades dos gestores da saúde que devem praticar políticas públicas hábeis a minimizar os danos que os limites orçamentários, em si, já trazem.

Entende-se, para este estudo, que as políticas públicas são conjuntos de atos administrativos voltados à instrumentalização das ações governamentais considerando determinações constitucionais e legais e podendo estar consubstanciadas em leis ou quaisquer outros atos normativos. Bucci ${ }^{7}$ assevera que "a política pública (...) define-se como o processo de escolha dos meios para a realização dos objetivos do governo, com a participação dos agentes públicos e privados".

Para a definição de políticas públicas, deve-se tomar em consideração demandas sociais, ISSN 1982-8829 Tempus, actas de saúde colet, Brasília, 11(4), 221-236,dez, 2017. Epub Ago/2018 
econômicas e políticas advindas dos vários setores da sociedade. ${ }^{7}$ Dessa, surgem, para a administração, três formas de governar: ou ela executa todas as tarefas correspondentes às demandas, o que é impossível, tendo em vista que as demandas são sempre crescentes e inconstantes; ou ela queda-se inerte, sem atitude, prejudicando toda a coletividade; ou ela escolhe, opta, entre tantas demandas, quais devem ter execução imediata e quais terão sua execução em momento ulterior. Nessa escolha, o princípio da discricionariedade torna-se doutrina essencial para a atuação do Poder Público. E esta, certamente, é a melhor atitude do governo de um Estado Social.

Segundo Pietro: ${ }^{8}$ existe discricionariedade quando a lei deixa à Administração a possibilidade de, no caso concreto, escolher entre duas ou mais alternativas, todas válidas perante o Direito. E essa escolha se faz segundo critérios de oportunidade, conveniência, justiça, equidade, razoabilidade, interesse público, sintetizados no que se convencionou chamar de mérito do ato administrativo.

O poder discricionário existe, portanto, quando a lei não dispõe sobre determinado fato cabendo, ao agente administrativo, a escolha entre diversas soluções para resolver o problema observandose sempre o interesse público e a obediência aos ditames legais. ${ }^{8}$ Logo, essa doutrina em muito se alinha ao dilema da administração pública, no caso em particular, da saúde enquanto política pública nacional. Ocorre, entretanto, que a tomada de decisão orientada por essa discricionariedade requer, do tomador de decisão, seja gestor ou jurista, uma análise criteriosa dos conhecimentos prévios para não confundir discricionariedade com arbitrariedade. Esta última se refere à atuação baseada em caprichos pessoais desvinculados de fundamentação lógica. O cerne diferencial entre a discricionariedade permitida e a arbitrariedade proibida é a motivação. Nessa, ou não existem motivos ou eles são incoerentes com os princípios administrativos. ${ }^{9}$

A discricionariedade permitida ao agente é, de certa forma, "vinculada", na medida em que ele, com base nas suas qualidades técnicas para a apreciação do caso concreto, opta pela melhor opção sempre vinculada ao interesse público. ${ }^{8}$

Para esses modos de atuação, é extremamente oportuno o papel indutor do SUS estimulando mudanças na formação profissional em saúde de acordo com seus interesses e necessidades. ${ }^{10}$ Entretanto, entende-se que a ressignificação da formação não deve se limitar aos profissionais da saúde. Consonante, Fernandes $\mathrm{Neto}^{11}$ anuncia, como uma das lacunas na formação jurídica, a área de Direito Sanitário.

Por Direito Sanitário entende-se o estudo das normas, princípios, doutrina e jurisprudência aplicáveis às Ciências da Saúde. Envolve, por exemplo, a legislação do SUS, mas não se limita à visão normativa sobre a ciência. ${ }^{11} \mathrm{O}$ mesmo não se confunde, portanto, com a noção de Direito à Saúde, a qual se refere ao conjunto de direitos subjetivos que possui uma pessoa em ser agraciada com políticas públicas de saúde. 
Isso incita compreender a relação entre os termos, uma vez que o Direito Sanitário tem interesse tanto pelo direito à saúde, "enquanto reivindicação de um direito humano, quanto pelo direito da saúde pública", apropriando-se de normas jurídicas com o objetivo da promoção e recuperação da saúde, quanto da prevenção de doenças. ${ }^{12}$

Amaral ${ }^{13}$ identifica a insuficiência do ensino do Direito Sanitário nos cursos de graduação no Brasil e que as parcas experiências de ensino nessa área estão focadas em cursos de curta duração e/ou especializações concentradas na Região Sudeste.

A superação desses desafios, na formação dos profissionais que atuam frente à implementação do direito à saúde, requer parceria entre serviços de saúde e academia no sentido de repensar as intervenções necessárias reorientando estratégias e modos de ensinar e aprender propiciando, portanto, a introdução das dimensões ética e política no saber e no fazer crítico da gestão em saúde. ${ }^{14}$ Compreende-se que a gestão em saúde se efetiva em uma relação estreita entre profissionais da saúde e o seu assessoramento, a exemplo do profissional do Direito.

Ao considerar que, dentre os profissionais de saúde, o profissional de Enfermagem é aquele que ocupa mais espaços estratégicos na gestão do SUS, ${ }^{15,16,17}$ urge a necessidade de desenvolver competências nesse com vistas à eficácia, efetividade e segurança, para que se possa dar efetivo cumprimento aos princípios do SUS e da administração pública, a fim de que cada decisão na saúde possa ser tomada com o maior grau de certeza possível. ${ }^{11}$

Para que esses profissionais, tanto do Direito, quanto da Enfermagem, desenvolvam as competências esperadas para tomar as melhores decisões, faz-se necessário que, desde a graduação, essas temáticas sejam incorporadas ao currículo de ambas categorias profissionais. Profissionais da saúde e do direito, integrados, muito poderão fazer nessa área. Fernandes Neto ${ }^{11}$ realça que o embasamento científico das decisões poderá ter implicações jurídicas, econômicas, clínicas e sociais que possam, em última instância, contribuir para a consecução do Direito à Saúde. Assim, o Direito Sanitário constitui-se como uma área de estudo que merece destaque e que deve ganhar espaço no cenário das políticas públicas brasileiras. ${ }^{18}$

A partir desse recorte epistemológico, delineia-se, como objeto desta pesquisa, a formação do bacharel em Direito e em Enfermagem para a atuação na área do Direito Sanitário. Disso, desdobram-se os questionamentos: Como essa formação se expressa nas matrizes curriculares? E no perfil docente? Há visibilidade dessa formação na concepção dos docentes e discentes?

Delineia-se, portanto, o objetivo deste estudo: analisar o ensino do Direito Sanitário nos bacharelados em Enfermagem e em Direito. Para a consecução deste, entende-se ser necessário trilhar os caminhos da abordagem qualitativa que, por sua natureza, requer a utilização de fontes de coleta de dados envolvendo diferentes participantes e documentos envolvidos com o objeto em análise.

ISSN 1982-8829 Tempus, actas de saúde colet, Brasília, 11(4), 221-236,dez, 2017. Epub Ago/2018 


\section{METODOLOGIA}

Estudo exploratório, compreensivo e documental, de natureza qualitativa, realizado no período de maio de 2015 a fevereiro de 2016 nos cursos de Direito e Enfermagem em um Estado do Nordeste brasileiro. Informações contidas no site do e-MEC sinalizam que o estado de desenvolvimento do estudo apresenta 16 Instituições de Ensino Superior - IES que ofertam, concomitantemente, os cursos de Enfermagem e Direito. ${ }^{19}$ Para delimitar o cenário do estudo, foram adotados os critérios de inclusão: IES reconhecidas pelo Ministério da Educação (MEC), situadas no cenário do estudo, que ofertassem os cursos de Direito e Enfermagem com nota igual ou superior a quatro no Exame Nacional de Desempenho de Estudantes (ENADE) imediatamente anterior à coleta de dados. Foram identificadas três IES que atendiam aos critérios. Todas as instituições que atenderam aos critérios de inclusão são universidades públicas.-

As unidades de análise foram os Projetos Pedagógicos dos Cursos (PPC) e docentes e discentes dos cursos de Enfermagem e Direito.

De tal modo, a coleta de informações ocorreu a partir das etapas a seguir. 1) Análise Documental dos Projetos Pedagógicos dos Cursos - Os PPC's dos cursos de Enfermagem e Direito selecionados, totalizando seis, foram submetidos a uma análise guiada por instrumento criado pelos autores com base no objetivo do estudo. O roteiro do instrumento visava a apreender informações relativas ao ensino de Direito Sanitário (módulos ou disciplinas que contemplam o ensino do Direito Sanitário com respectivas cargas horárias e semestres; conteúdos abordados em disciplinas ou módulos que identificam relação com o Direito Sanitário; grupo, linha ou projeto de pesquisa na área de Direito Sanitário; atividades de Extensão e Complementares (seminários, cursos, congressos etc.) que contemplam o ensino do Direito Sanitário com respectivas cargas horárias. 2) Aplicação de questionário on-line aos docentes e discentes - O roteiro utilizado visou a captar as informações referentes ao ensino do Direito Sanitário sob o olhar discente e docente. Realizou-se um levantamento do quantitativo de docentes e de discentes que estavam matriculados no último semestre de seu respectivo curso no período da coleta de dados e seus contatos eletrônicos. Foram, então, identificados 231 docentes e 296 discentes de ambos os cursos. Os questionários e Termos de Consentimento Livre e Esclarecido - TCLE foram encaminhados aos e-mails dos docentes e discentes via sistema survey monkey. Com a finalidade de garantir o anonimato da pesquisa, não houve registro de identificação do respondente, ou seja: não foi vinculada a participação à pesquisa com o e-mail enviado.

Salienta-se que a utilização de questionários virtuais apresenta viés em razão do percentual de devolução que, por vezes, é menor que o esperado. Diante disso, recomenda-se um retorno percentual mínimo de $25 \%{ }^{20}$ para fins de confiabilidade nos dados de um determinado estudo. Neste estudo, o percentual de retorno dos questionários foi de 189 (35,9\%) participantes. Destes, $108(57,2 \%)$ eram discentes e $81(42,8 \%)$, docentes. Isso representa adequação do estudo no que 
se refere à confiabilidade dos dados de uma pesquisa que utiliza questionários virtuais.

A análise do material coletado foi orientada pela técnica de Análise Temática, ${ }^{21}$ que se estrutura nas etapas: (1) ordenação dos dados, que engloba o conteúdo das observações realizadas e o levantamento documental e bibliográfico referentes ao tema; (2) classificação dos dados obtida com base em uma fundamentação teórica estabelecendo uma relação dialético-interpretativa entre eles e (3) análise final, que transitou entre o concreto e o abstrato, o particular e o geral das informações recolhidas no campo de pesquisa.

Estudo aprovado por Comitê de Ética em Pesquisa sob o Parecer N. ${ }^{\circ} 1.136 .685 / 2015$. Ressaltase que, para manter o anonimato dos participantes, estes foram identificados segundo a ordem de transcrição das informações dos discentes (d) e dos docentes (D) com a indicação do respectivo curso ao qual estão vinculados (d1-Enf ou D1-Dir, por exemplo).

\section{RESULTADOS E DISCUSSÃO}

Ao considerar os critérios de exaustividade, representatividade, homogeneidade, pertinência e exclusividade das informações, foram identificadas as categorias: "Nuances da formação em Direito Sanitário nos bacharelados de Enfermagem e Direito" e "Ensino do Direito Sanitário nos bacharelados de Enfermagem e Direito: vozes dos docentes e discentes".

\section{Nuances da formação em Direito Sanitário nos bacharelados de Enfermagem e Direito}

A análise dos Projetos Pedagógicos dos cursos de Enfermagem e Direito demonstrou a incipiência na indução da formação para o campo do Direito Sanitário, fato possível de constatação a partir da inexistência de oferta de disciplina ou módulo de Direito Sanitário ou Direito à Saúde nos seis cursos estudados. A opção pela busca com os dois termos deveu-se à compreensão de que o Direito Sanitário está intrinsecamente relacionado ao Direito à Saúde, ${ }^{13}$ mas reforça-se o entendimento que não podem ser tidos como sinônimos. A escolha pelos dois termos deu-se na intenção de identificar quaisquer aspectos que vislumbrassem uma intencionalidade em abordar aspectos importantes ao ensino do Direito Sanitário nos cursos.

Igualmente, a busca da presença de conteúdos afins ao Direito Sanitário/Direito à Saúde, em disciplinas ou módulos, pode ser analisada a partir do quadro 1. 
Quadro 1. Expressões textuais que sugerem o ensino do Direito Sanitário presentes nos Projetos Pedagógicos dos cursos de Enfermagem e Direito estudados.

\begin{tabular}{|c|c|c|c|c|c|c|}
\hline IES & Curso & Disciplinas/módulos & Caráter & Período & $\begin{array}{l}\text { Carga Horária } \\
\text { ( d i s c i p l i n a / } \\
\text { módulo) }\end{array}$ & $\begin{array}{l}\text { C o n t e ú d o s } \\
\text { correlatos ao Direito } \\
\text { Sanitário/Direito à } \\
\text { saúde }\end{array}$ \\
\hline \multirow[b]{2}{*}{1} & \multirow{2}{*}{ Enfermagem } & $\begin{array}{l}\text { Princípios de } \\
\text { Sociologia da Saúde }\end{array}$ & Obrigatória & $2^{\circ}$ & $64 \mathrm{~h}$ & $\begin{array}{l}\text { Historia da } \\
\text { construção social dos }\end{array}$ \\
\hline & & $\begin{array}{ll}\text { Enfermagem } & \text { em } \\
\text { saúde coletiva } & \end{array}$ & $\begin{array}{l}\text { Obrigatória } \\
* * *\end{array}$ & $5^{\circ}$ & $64 \mathrm{~h}$ & $\begin{array}{l}\text { modelos de saúde. } \\
\text { Historico da saúde } \\
\text { pública. }\end{array}$ \\
\hline \multirow{3}{*}{2} & Enfermagem & $\begin{array}{l}\text { Atenção Básica à } \\
\text { Saúde }\end{array}$ & Obrigatória & $1^{\circ}$ ao $3^{\circ}$ & $60 \mathrm{~h}$ (por semestre) & $\begin{array}{l}\text { Reforma sanitária; } \\
\text { Sistema Único de } \\
\text { Saúde, as diretrizes e } \\
\text { os objetivos; Políticas } \\
\text { públicas de saúde e } \\
\text { Leoislacão em saúde }\end{array}$ \\
\hline & & Envelhecimento & Obrigatória & $6^{\circ}$ & $160 \mathrm{~h}$ & Leis de Amparo e \\
\hline & Direito & $\begin{array}{lllllll}\mathrm{D} & \mathrm{i} & \mathrm{r} & \mathrm{e} & \mathrm{i} & \mathrm{t} & \mathrm{O} \\
\text { Previdenciário } & & & & \end{array}$ & Optativa & $\begin{array}{l}\text { A partir } \\
\text { do } 5^{\circ}\end{array}$ & $60 \mathrm{~h}$ & $\begin{array}{l}\text { Principios e diretrizes } \\
\text { que regulamentam } \\
\text { o SUS e o acesso à } \\
\text { saúde; Lei Orgânica }\end{array}$ \\
\hline \multirow{3}{*}{3} & & $\begin{array}{l}\text { Sociologia aplicada à } \\
\text { saúde }\end{array}$ & Obrigatória & $2^{\circ}$ & $60 \mathrm{~h}$ & $\begin{array}{l}\text { da Saúde No } 8.080 / 90 \text {. } \\
\text { Direito Social e à } \\
\text { Saúde. }\end{array}$ \\
\hline & Enfermagem & $\begin{array}{l}\text { Enfermagem no } \\
\text { processo de cuidar } \\
\text { em saúde coletiva I } \\
\text { e II }\end{array}$ & Obrigatória & $7^{\circ}$ & $\begin{array}{l}\mathrm{I}-90 \mathrm{~h} \\
\mathrm{II}-180\end{array}$ & $\begin{array}{l}\text { Saúde Pública; Saúde } \\
\text { Coletiva. }\end{array}$ \\
\hline & Direito & 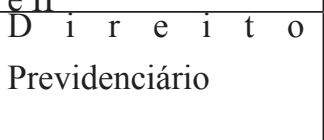 & Optativa & $10^{\circ}$ & $60 \mathrm{~h}$ & $\begin{array}{l}\text { Assistência social e à } \\
\text { saúde na Constituição } \\
\text { de } 1988\end{array}$ \\
\hline
\end{tabular}

Fonte: dados da pesquisa.

** Não foram identificadas disciplinas/módulos que sugerem evidências do ensino do Direito Sanitário no curso.

As evidências sinalizam que a abordagem do Direito Sanitário e/ou Direito à Saúde nos cursos de Enfermagem das IES concentra-se na apropriação do Direito à Saúde como campo de discussão sustentado nas prerrogativas legais da CF e das Leis Organizativas da Saúde. É possível inferir, ainda, que o ensino do Direito Sanitário é explorado a partir de conteúdos estruturantes para o entendimento do Direito à Saúde enquanto premissa social, em especial, quando se propõe discutir a conjuntura social e sua repercussão no que se considera saúde de um local/país.

Entretanto, o Direito Sanitário enquanto instrumento de operacionalização do Direito à Saúde não é diretamente objeto de estudo nos cursos de Enfermagem analisados. Isso pode influenciar, 
consideravelmente, o lidar com diversos processos que permeiam o acesso à saúde.

A formação profissional em Enfermagem precisa considerar a generalização, a diferenciação, o reconhecimento, a intersubjetividade e a interdisciplinaridade. ${ }^{22}$ Essa premissa demonstra que o Direito Sanitário, a exemplo de outros campos do conhecimento, não pode ser en passant na formação do enfermeiro visto que o objetivo maior do seu processo de trabalho é a produção de saúde e esta é estritamente dependente da compreensão de saúde enquanto direito.

Com a análise direcionada para os PPC's dos cursos de Direito, foi possível identificar, em dois desses cursos, a disciplina Direito Previdenciário, de caráter optativo, na qual abordavamse aspectos diferentes relacionados ao Direito à Saúde. O ementário de uma dessas disciplinas faz referência à Constituição Federal de 1988 voltada à assistência social e à saúde. No conteúdo programático da referida disciplina, em outra IES, identificou-se a unidade denominada "A Saúde" com a discussão acerca dos princípios e diretrizes do SUS na garantia do acesso à saúde. O exposto é um indicativo da inclusão da legislação do SUS em dois dos três cursos de Direito estudados.

No entanto, destaca-se que o ensino do Direito Sanitário vinculado unicamente à oferta de disciplinas optativas implica a dependência do interesse do aluno à incorporação dessa formação, visto que o caráter optativo conferido a disciplinas de cursos de graduação se propõe ampliar a formação profissional, de livre escolha do aluno, dentre o rol de disciplinas ofertadas para o curso. ${ }^{23}$

Além disso, em dois dos três PPC's dos cursos de Direito, o termo "saúde" também foi identificado em disciplinas que não estabelecem relação direta com o estudo da saúde enquanto direito fundamental, mas pode contribuir para a atuação profissional do operador do Direito, a saber: Direito Penal, Direito Municipal e Direito do Consumidor.

A relação que o Direito Sanitário guarda com outros ramos do Direito parte do sentido de definir, com a maior precisão possível, o conceito jurídico de saúde. Somente, com isso, poderá oferecer os contornos jurídicos da saúde como um direito fundamental e determinar a amplitude dos deveres do Estado para a efetivação desse direito. ${ }^{24}$

Ao analisar o período de oferta de disciplinas com conteúdos correlatos ao Direito Sanitário e ao Direito à Saúde, observa-se que, nos cursos de Enfermagem estudados, há uma diversidade nos semestres de oferta mostrando um itinerário que vai do primeiro ao sétimo semestres, com ênfase nos primeiros semestres, a depender de cada IES. Situação diferente ocorre nos cursos de Direito, onde a oferta deu-se a partir do quinto semestre.

A formação profissional trata-se de um desenvolvimento intelectual, processo lento e gradual, para o alcance do ser profissional..$^{22}$ Portanto, o ensino do Direito Sanitário não deve se concentrar em semestres iniciais ou finais e, sim, possuir um caráter de continuidade no itinerário da formação do acadêmico no curso. 
Registra-se que, nos PPC's analisados de ambos os cursos, não foi possível identificar marcas textuais de evidências de pesquisa e de extensão no campo do Direito Sanitário e Direito à Saúde. Exploraram-se essas dimensões da pesquisa e da extensão junto aos docentes e discentes. De todo modo, considerando a tríade de sustentação da formação acadêmica, conclui-se que, pelos PPC's, é incipiente o ensino e inexistente a pesquisa e a extensão acerca do Direito Sanitário/Direito à Saúde nos cursos estudados.

O ensino, a pesquisa e a extensão, enquanto atividades complementares e interdependentes, precisam ter valorações equivalentes no sistema universitário, sob o risco de desenvolver conhecimento reducionista. A qualidade e o sucesso dos profissionais formados dependem do nível de interação e articulação entre esses três pilares do conhecimento influenciado por uma formação sistêmica. ${ }^{25}$

Cabe mencionar que não foi possível identificar a carga horária destinada ao ensino do Direito Sanitário, pois não havia, nos PPC's, a indicação de carga horária para explorar os conteúdos evidenciados como correlatos à temática.

\section{Ensino do Direito Sanitário nos bacharelados de Enfermagem e Direito: vozes dos docentes e discentes}

A visão que docentes e discentes dos cursos de Enfermagem e Direito apresentam acerca do ensino do Direito Sanitário alinha-se aos dados discutidos na sessão anterior, ou seja: há uma (in) visibilidade daquele nos cursos analisados. Cem dos 189 participantes afirmaram a inexistência do ensino do Direito Sanitário na formação de bacharéis em Enfermagem e em Direito. Além disso, para 89 participantes, o Direito Sanitário é conteúdo associado a outras temáticas, não configurando uma disciplina específica ou conteúdo estudado longitudinalmente no processo formativo traduzindo, aqui, a inexpressividade do ensino sobre o Direito Sanitário.

Essas interpretações sinalizam as linhas de discussão que serão apresentadas nesta categoria: a inexistência e a inexpressividade do ensino do Direito Sanitário nos bacharelados de Direito e Enfermagem.

Nos cursos de Direito e Enfermagem, 62 discentes e 38 docentes apontam a inexistência do ensino da temática Direito Sanitário nas matrizes curriculares. Isso se torna evidente a partir das falas a seguir.

\footnotetext{
“Não acontece em nenhum dos módulos.” (d31-Enf)

"Não existe essa disciplina no meu curso." (d43-Enf)
}

"Não é do meu conhecimento nenhuma abordagem sistemática desse tema no curso de Enfermagem." (D17-Enf) 


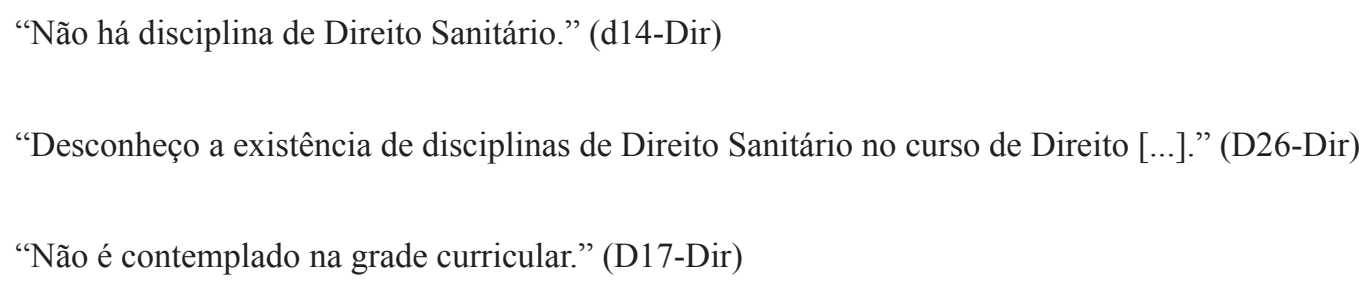

O reconhecimento da proteção constitucional do Direito à Saúde só foi possível após longa luta política que contou com a atuação do Movimento pela Reforma Sanitária ocorrida de forma simultânea ao processo de redemocratização. A Constituição Federal de 1988, afinada com a evolução constitucional contemporânea e com o Direito Internacional, incorporou o Direito à Saúde em seu texto, consagrando-o como direito fundamental, e outorgou-lhe uma proteção jurídica no âmbito da ordem jurídico-constitucional, sendo assumido como um direito de todos e um dever do Estado. ${ }^{26}$

Assim, a conjuntura atual é propícia para uma reflexão sobre o papel e a importância do estudo do Direito Sanitário que, a par de sua inegável importância, sobretudo a partir da previsão do Direito à Saúde na CF e do fenômeno da judicialização da saúde nos últimos anos, ainda representa uma lacuna nos cursos de Direito e até mesmo nos cursos de formação de outros profissionais que lidam com o tema, a exemplo da Enfermagem. ${ }^{26}$

Além da ausência do ensino do Direito Sanitário nos projetos pedagógicos e matrizes curriculares se configurar como um dos problemas da formação superior no Brasil ${ }^{24}$, neste estudo mencionamse situações em que ele se manifesta de maneira deficiente.

Para 46 discentes e 43 docentes, o ensino do Direito Sanitário ocorre de forma inexpressiva. Esta se manifesta a partir de duas perspectivas: a abordagem diluída do Direito Sanitário em outras(os) disciplinas/módulos e a interpretação equivocada do significado do Direito Sanitário.

Assim, como na análise dos PPC's, não existe disciplina/módulo específico de Direito Sanitário nos cursos nos quais ligeiras discussões se acham por dar conta do conteúdo a ser explorado. Além disso, docentes e discentes sinalizam que o Direito Sanitário, quando manifestado nos cursos, ocorre por meio de disciplinas optativas ou eletivas e que estas ainda podem não ser ofertadas.

“Não existem disciplinas específicas que abordem o tema.” (d37-Enf)

"No curso, há disciplinas que contemplam o Direito Sanitário tais como Saúde Coletiva, Políticas Públicas e Atenção Primária à Saúde.” (D5-Enf)

"Minha turma teve a oportunidade de ter um módulo eletivo que teve alguns conteúdos que abordaram esta temática.” (d47-Enf)

“Como disciplina optativa." (d19-Dir)

ISSN 1982-8829 Tempus, actas de saúde colet, Brasília, 11(4), 221-236,dez, 2017. Epub Ago/2018 
“Acho que é disciplina optativa, mas não é disponibilizada.” (d20-Dir)

O Direito à Saúde enquanto direito social fundamental adquirido tem sua efetivação dependente, intrinsecamente, da atuação do Estado enquanto promotor de "políticas sociais e econômicas que visem à redução do risco de doença e de outros agravos e ao acesso universal e igualitário às ações e serviços para sua promoção, proteção e recuperação". ${ }^{1}$

Para que o Direito à Saúde seja efetivado, faz-se necessário um conjunto de normatizações para a sua consecução. Adentra-se, assim, ao Direito Sanitário, entendendo este como um congregador das normas relacionadas ao ordenamento jurídico que regulamentam o Direito à Saúde. ${ }^{27}$

Essa tênue relação entre os conceitos pode ser o fundamento das interpretações equivocadas presentes nas falas dos participantes do estudo nas quais se verificam o Direito Sanitário como um sinônimo de Direito à Saúde vinculado, unicamente, à discussão de políticas públicas de saúde e legislação do SUS.

\footnotetext{
“Acredito que o Direito à Saúde é contemplado nos módulos de Atenção Básica e Trabalho em Saúde e Desenvolvimento Humano e Profissional onde discutimos a saúde como um direito garantido em Constituição Federal...” (d27-Enf)
}

“A mais próxima se chama Políticas Públicas de Saúde [refere-se a uma disciplina].” (d3-Dir)

"Discutido ainda de forma incipiente, mas de forma transversal, principalmente nos módulos de Atenção Básica em Saúde.” (D34-Enf)

Os posicionamentos permitem inferir que o Direito Sanitário vem ligado a estudos de aspectos contextuais da saúde na sociedade, em especial, ao que remete a políticas de saúde enquanto um mapa de ações sobre como se agir para a garantia da qualidade de vida das pessoas. Com relação à qualidade de vida, um conceito exalta-se quando se reflete o ensino do Direito Sanitário: o meio ambiente.

“... eu percebo um grande desconhecimento dos alunos sobre o Direito Sanitário. O máximo que eles sabem é que há um direito à saúde e um direito a um meio ambiente saudável e equilibrado, mas não sabem como efetivar esses direitos e nem sabem muito sobre os limites desses direitos.” (D11-Dir)

"Vislumbro a sua menção [direito sanitário] apenas na disciplina de Direito Ambiental.” (D20-Dir)

"Não lembro de ter visto o conceito de Direito Sanitário, mas temos a disciplina de saúde ambiental." (d13-Enf)

As falas expressam as áreas do Direito Sanitário, Direito Ambiental e Saúde Ambiental como apresentando o mesmo objeto de atuação. Apesar de serem instituídos por objetos diferentes meio ambiente e saúde -, possuem pontos de atuação convergentes, pois é possível identificar uma 
proximidade técnica entre esses ramos que se apoia em princípios e competências constitucionais distintos da CF 1988, uma vez que um visam à proteção do meio ambiente ecologicamente equilibrado, o que proporciona a qualidade de vida, enquanto o outro procura identificar problemas ambientais que possam oferecer prejuízos à qualidade de vida. ${ }^{1}$

É nesse contexto que se discute o meio ambiente como um dos fatores determinantes e condicionantes da saúde, uma vez que esta engloba condições que devem estar apropriadas para o bem-estar completo do ser humano. Assim, qualquer dano causado ao meio ambiente provoca prejuízo à saúde pública e vice-versa. ${ }^{28}$

Desse modo, tomando a saúde como um direito de todos, situada dentro de um contexto amplo e influenciada por inúmeros determinantes sociais, é que o Direito Sanitário apresenta diversos olhares com vistas a abarcar a complexidade embutida no conceito de saúde, que depende de múltiplos fatores para sua efetiva garantia.

\section{CONSIDERAÇÕES FINAIS}

A análise junto aos PPC's sinalizou a incipiência na indução da formação para o campo do Direito Sanitário constatada pela inexistência de disciplinas/módulos sobre esta temática. Outra evidência sinalizada pelo estudo é a vinculação do ensino do Direito Sanitário a partir de conteúdos estruturantes para o entendimento do Direito à Saúde. Quando identificados aspectos do Direito Sanitário no ensino desses cursos, este está associado a disciplinas optativas/eletivas, que nem sempre são ofertadas, ou conteúdos tratados marginalmente, característica que sinaliza uma formação à margem do necessário para um profissional que pode vir a lidar com situações que envolvam a necessidade de fundamentos do Direito Sanitário. Pontua-se ainda que, nos PPC's analisados de ambos os cursos, não foi possível identificar práticas de pesquisa e de extensão no campo do Direito Sanitário.

As informações advindas dos docentes e discentes evidenciaram dois desdobramentos do ensino do Direito Sanitário nos cursos analisados: a inexistência e a inexpressividade. A inexistência denotou a lacuna na formação dos profissionais que lidam mais diretamente com situações que envolvem o Direito Sanitário configurando-se em um problema da formação superior no Brasil. Essa reflexão repousa, especialmente, quando se infere a relação intrínseca entre a formação profissional e necessidades de saúde da população, permitindo vislumbrar o descompasso existente, já que o fenômeno da judicialização da saúde é crescente no Brasil.

Ao considerar a inexpressividade, os resultados do estudo apresentam uma abordagem diluída do Direito Sanitário em outras(os) disciplinas/módulos e, quando da ocorrência do ensino, dá-se por meio de disciplinas optativas ou eletivas, que podem ser ofertadas ou não. Também foi identificada uma interpretação equivocada do significado do Direito Sanitário, tido como sinônimo de Direito à Saúde e vinculado unicamente à discussão de políticas públicas de saúde e da legislação do SUS 
para a garantia da qualidade de vida das pessoas.

O estudo apresenta algumas limitações quanto à aplicação do questionário on-line por considerar, hoje, a necessidade de aproximações mais aprofundadas na realidade do ensino do Direito Sanitário e no desconhecimento dos sujeitos sobre o tema em voga, que revela uma lacuna para a investigação no campo da formação em Enfermagem e Direito dificultando a aquisição de informações condizentes com a discussão do Direito Sanitário.

Desse modo, recomenda-se a reali

zação de estudos que busquem explorar mais o assunto e dar visibilidade às discussões para, assim, alinharem-se as necessidades de saúde com provocações na academia e estas para/em transformações sociais para indivíduos e coletividades na busca constante da saúde enquanto direito.

\section{REFERÊNCIAS BIBLIOGRÁFICAS}

1. Brasil. Constituição (1988). Constituição da República Federativa do Brasil. Brasília, DF: Senado Federal: Centro Gráfico, 1988. p. 116-117.

2. Brasil. Conselho Nacional de Secretários de Saúde. Legislação do SUS / Conselho Nacional de Secretários de Saúde. - Brasília: CONASS, 2003 [cited 2016 jul 10].p. 23. Available from: http://bvsms.saude.gov.br/bvs/publicacoes/progestores/leg_sus.pdf.

3. Magalhães Júnior HM. Apresentação. In: SANTOS, L.; ANDRADE, L. O. M. SUS: o espaço da gestão inovada e dos consensos interfederativos - aspectos jurídicos, administrativos e financeiros. Campinas: Instituto de direitos sanitários, 2007. p.7.

4. D’ávila,LS, Saliba GR. A efetivação do direito à saúde e sua interface com a justiça social. Rev direito sanit. 2017;17(3):15-38.

5. Nunes FA. Judicialização da saúde. 2014. Monografia (Curso de Práticas Judiciais)Universidade Estadual da Paraíba, Campina Grande, 2014.

6. Gotlieb V, Yavich N, Báscolo E. Litígio judicial y el derecho a la salud em Argentina. Cad Saude Publica. 2016[cited 2016 nov 15];32(1):1-12. Available from: http://www.scielo.br/pdf/ csp/v32n1/0102-311X-csp-0102-311X00121114.pdf.

7. Bucci MPD. O Conceito de Política Pública em Direito. In: Bucci MPD. Políticas Públicas - Reflexões sobre o conceito jurídico. São Paulo: Saraiva, 2006. p. 76.

8. Pietro MSZ. Discricionariedade Técnica e discricionariedade administrativa. In: Carlin VI. (Org.). Grandes Temas de Direito Administrativo. Florianópolis: Conceito Editorial, 2009. p. 612. 
9. Meirelles HL. Direito Administrativo Brasileiro. 29. ed. atual. São Paulo: Malheiros, 2004.

10. Campos FE, et al. Caminhos para Aproximar a Formação de Profissionais de Saúde das Necessidades da Atenção Básica. Rev Bras de Edu Méd. 2001;25(2):53-9.

11.Fernandes Neto AJ. Judicialização da saúde. Caderno Mídia e Saúde Pública. 2007;2:48-51.

12.Dallari SG. Direito sanitário. In: Brasil. Ministério da Saúde. Direito sanitário e saúde pública. v.1, Coletânea de textos. Brasília: Ministério da Saúde, 2003.

13. Amaral MF. O direito sanitário no Brasil: um panorama do ensino especializado e sua práxis restrita. Cadernos Ibero-americanos de direito sanitário. 2015;4(4):105-22.

14. Minas Gerais. Universidade Federal de Minas Gerais. Resolução no 14, 20 de março de 2012. Regulamenta os percursos de integralização do curso de graduação em Direito. Belo Horizonte, 2012.

15. Peres AM, Ciampone MHT. Gerência e competências gerenciais do enfermeiro. Texto Contexto Enferma, 2006[cited 2016 may 13];15( 3): 492-99. Available from: http://www.scielo.br/ $\mathrm{pdf} / \mathrm{tce} / \mathrm{v} 15 \mathrm{n} 3 / \mathrm{v} 15 \mathrm{n} 3 \mathrm{a} 15$.

16. Melo CMM, Santos TA. A participação política de enfermeiras na gestão do sistema único de saúde em nível municipal. Texto Contexto Enferm.2007[cited 2016 aug 15];16(3):426-32. Available from: http://www.scielo.br/pdf/tce/v16n3/a07v16n3.pdf.

17. Souza MKB, Melo CMM. A atuação das enfermeiras na macrofunções gestoras em saúde. Revista de enfermagem da UERJ. 2009;17(2):198-202.

18. Dias MSA, et al. Judicialização da saúde pública brasileira. Rev. Bras. Polít. Públicas (Online). 2016[cited 2016 nov 10];6(2):132-145. Available from: http://www. publicacoesacademicas.uniceub.br/RBPP/article/view/4012/pdf.

19. Brasil. Ministério da Educação. E-mec: instituições de educação superior e cursos cadastrados. Brasília, DF, 2016[cited 2016 apr 10]. Avilable from: http://emec.mec.gov.br/. Acesso em: 10 abr. 2016.

20. Marconi MA, Lakatos EM. Fundamentos de metodologia científica. São Paulo: Atlas, 2010.

21. Minayo MCS. O desafio do conhecimento: pesquisa qualitativa em saúde. 13 ed. São Paulo: Hucitec, 2013.

22.Nunes ECDA, Silva LWS, Pires EPOR. O ensino superior de enfermagem: implicações da formação professional par o cuidado transpessoal. Rev. Latino-Am. Enfermagem. 2011:19(2):1-9. 
23. Minas Gerais. Universidade Federal de Minas Gerais. Resolução no 14, 20 de março de 2012. Regulamenta os percursos de integralização do curso de graduação em Direito. Belo Horizonte, 2012.

24. Aith FMA, et al. Direito sanitário: saúde e direito, um diálogo possível. Belo Horizonte: ESP-MG, 2010 [cited 2016 oct 02]. Available from: http://www.esp.mg.gov.br/wp-content/ uploads/2012/06/Direito-sanitario_Final.pdf.

25. Pivetta S. Políticas públicas e a construção do conteúdo material do direito à saúde: desafio à Administração Pública brasileira. Revista de Direito Administrativo e Constitucional. 2010;10(41):209-30.

26. Franco LFG. Direito sanitário é relevante e deve ser estudado. Revista Consultor Jurídico (online). 2013[cited 2016 sep 10];26. Available from: http://www.conjur.com.br/2013-ago-26/ luis-franco-direito-sanitario-materia-relevante-estudada.

27. Gorrilhas LM. Do direito saúde ao direito sanitário. Revista Jus Navengandi, Teresina. 2010[cited 2016 nov 17]; 15. Avilable from: https://jus.com.br/artigos/14686/do-direito-a-saudeao-direito-sanitario

28. Cunha PR. A relação entre meio ambiente e saúde e a importância dos princípios de prevenção e da precaução. Rev. Jus Navegandi. 2005[cited 2016 oct 11];10. Available from: https://jus.com.br/artigos/6484.

Artigo apresentado em 10/11/2017

Artigo aprovado em 01/02/2018

Artigo publicado no sistema em 30/08/2018 